Research Article

\title{
Comparison of cardiovascular safety of escitalopram and sertraline based on electrocardiographic alterations: a pharmacovigilance study
}

\author{
Balwant K. Choure ${ }^{1}$, Girish T. Raparti ${ }^{2}$, Jayprakash B. Ramanand ${ }^{1}$, Jyoti B. Tapase ${ }^{3}$, \\ Praveenkumar T. Patil ${ }^{4}$, Nitin N. Puram ${ }^{1}$, Rama R. Bhosale ${ }^{1}$
}

${ }^{1}$ Department of Pharmacology, RCSM GMC, Kolhapur,

Maharashtra, India

${ }^{2}$ Department of Pharmacology, Ashwini Rural MCH and RC, Solapur, Maharashtra, India ${ }^{3}$ Department of Swasthavritta, KC Ajmera Ayurved Mahavidyalaya, Dhule, Maharashtra, India

${ }^{4}$ Department of Pharmacology, SBH GMC, Dhule, Maharashtra, India

Received: 08 July 2016

Revised: 12 July 2016

Accepted: 15 July 2016

*Correspondence to:

Dr. Balwant K. Choure,

Email:drchourebk@gmail.com

Copyright: () the author(s), publisher and licensee Medip Academy. This is an openaccess article distributed under the terms of the Creative Commons Attribution NonCommercial License, which permits unrestricted noncommercial use, distribution, and reproduction in any medium, provided the original work is properly cited.

\begin{abstract}
Background: Escitalopram and sertraline are the most commonly prescribed antidepressant drugs, belongs to SSRI class. Both the drugs are long been considered as free from cardiovascular adverse effects. Recently number of studies reported potential association between these drugs and pronounced cardiovascular adverse effects. ECG changes like prolongation of QT interval are frequently used as markers for the increased risk of a fatal cardiac arrhythmia. The potential cardiovascular adverse reaction profile of both these drugs is little studied in Indian rural population.

Methods: This was a 6 weeks prospective open label observational study carried out in a drug naive 209 patients receiving either escitalopram $(n=106)$ or sertraline $(n=103)$. ECG parameters like heart rate, RR interval, PQ/PR interval, QRS duration and QTc interval, were obtained directly from the digital machine recordings, additionally the QT interval was measured manually with the help of caliper. Statistical analysis was done by using Statistical software SPSS 17.0. Results: Out of 209 drugs naive patients, 12 from escitalopram group and 10 patients from Sertraline were lost to follow-up. Hence ECG recordings of the remaining 94 patients under escitalopram group, 93 patients under sertraline group were used for study analysis. The ECG alterations caused by the escitalopram were compared with that caused by sertraline. It was observed that the differences between the ECG alterations caused by either of escitalopram or sertraline were statistically non-significant.

Conclusions: It was concluded, at therapeutic doses neither of the drugs have the potential risk of drug induced arrhythmias, throughout the study.
\end{abstract}

Keywords: ECG, Arrhythmia, Escitalopram, Sertraline, QTc

\section{INTRODUCTION}

Escitalopram and sertraline are the most commonly prescribed antidepressant drugs, belongs to selective serotonin reuptake inhibitor (SSRI) class. ${ }^{1}$ Clinical studies with SSRIs like escitalopram and sertraline showed significant advantages over TCAs in producing fewer cardiotoxic, anticholinergic and antihistaminergic side effects in the treatment of major depressive disorders. $^{2}$

Both the drugs are considered to be free of cardiovascular adverse effects; hence these are widely used to treat most of depressive disorders in patients without as well as with cardiovascular compromise. But recently number of studies reported potential association between these drugs and pronounced cardiovascular adverse effects 
supported by various mammalian and human cardiovascular preparations by inhibiting cardiac and vascular $\mathrm{Na}^{+}, \mathrm{Ca}^{2+}$ and $\mathrm{K}^{+}$channels. ${ }^{3,4}$ Furthermore, an increasing number of case reports demonstrated 'a clinically significant' cardiovascular adverse effects associated with any of these drugs. ${ }^{5-7}$ Conversely, some studies failed to demonstrate any significant cardiovascular adverse effect. ${ }^{8,9}$ Sadhart study reported cardiovascular safety of sertraline in patients known cardiovascular co-morbidity like coronary artery disease or unstable angina which was supported by earlier safety study by Wilens et al. ${ }^{10,11}$

ECG changes like prolongation of QT interval which is frequently used as a marker for the increased risk of a fatal cardiac arrhythmia. ${ }^{12}$ Thus the findings on the 12 lead ECG have been useful for prediction of cardiac arrhythmias. $^{13}$

The potential cardiovascular adverse reaction profile of both of these drugs is little studied in rural population of India. ${ }^{14}$ So it was decided to evaluate the cardiovascular adverse effects of these drugs in depressed patients in rural tertiary care hospital, as a part of current pharmacovigilance program of India (PVPI) with the help of monitoring of ECG alterations due to these drugs.

\section{METHODS}

\section{Ethical declaration}

The study was started after taking approval from institutional ethics committee. The study was conducted in accordance with the Declaration of Helsinki.

\section{Setting}

It was a hospital based prospective observational study with active surveillance to monitor the ECG alterations whiles taking either escitalopram or sertraline in patients, irrespective of their diagnosis.

\section{Study design}

Allocation: Non-randomized

Endpoint: Classification safety study

Model: Single group assignment

Masking: Open label

Primary purpose: Prevention

\section{Study subjects}

All the successive drug naive patients those who were prescribed the treatment of either escitalopram or sertraline, irrespective of their diagnosis and those fulfilling inclusion criteria, were included in study. The decision regarding selection of drug for therapy for individual patients, advise for any investigation if required and change in drug therapy was ultimately based on psychiatrist's assessment of clinical circumstances and patient needs. Concomitant drug history if any was taken carefully before attributing the suspected ECG change to the respective drug.

\section{Inclusion criteria}

- Drug naive patients, who were prescribed drugs under study.

- Patients of either sex of age more than 18 years and less than 50 years.

- Patients who gave the informed consent to participate in study.

\section{Exclusion criteria}

- Female patients who were pregnant or lactating

- Body mass index more than $30.0 \mathrm{~kg} / \mathrm{m}^{2}$.

- H/o of substance abuse e.g. alcohol, nicotine, cocaine. $^{15,16}$

- H/o cardiovascular co-morbid illness e.g. Hypertension, angina, myocardial infarction, congestive heart failure, myocarditis etc.

- H/o sudden unexplained death at age <40 years in a first-degree relative.

- H/o any significant renal /hepatic/endocrine/ hematological disease.

- Conditions/disease supposed to cause ECG changes like bradyarrhythmias, predisposition to hypokalaemia and hypomagnesia.

- H/o medications that affect the ECG parameters.

- Patients taking more than two psychoactive drugs.

- Patients with abnormal ECG finding at baseline.

\section{Measurements and instruments}

Physical examination of each patient was done during first visit including recording of weight and height using weighing scale and inch-centimeter tape respectively. Vital signs viz. blood pressure (BP) and heart rate (HR) for every patient were recorded at baseline. All the instruments were calibrated regularly.

BPL Cardiart 6108 T ECG Machine (BPL Manufacturing Company, BPL limited, \&India) was used to for periodic ECG recording of each patient. All the measurements and recording were done during routine morning OPD hours i.e. between 9 am to $1 \mathrm{pm}$.

\section{Follow up}

Each patient enrolled for the study was evaluated at each scheduled follow up visits at 2 week and 6 week after initiation of drug therapy. At every follow up visits, ECGs were recorded for each patient with standard ECG recording procedure. 


\section{Drug administration}

Escitalopram was started at 5-10 $\mathrm{mg} /$ day and increased to $20 \mathrm{mg} /$ day at the end of the $2 \mathrm{nd}$ week of the treatment (visit II) and then continued with the same dose for rest of study duration. While the initial dose of sertraline was $50 \mathrm{mg} /$ day and the dose was increased to $100 \mathrm{mg} /$ day at the end of the 2 week (visit II) and then continued with the same dose. Patients were not allowed to take concomitant medications; however, in cases of sleep disturbances or increased anxiety, patients were allowed to take low doses of clonazepam $(0.5 \mathrm{mg})$, when required.

\section{Analysis of ECG}

Most of the ECG parameters like heart rate, RR interval, $\mathrm{PQ} / \mathrm{PR}$ interval, QRS duration and QTc interval, were obtained directly from the digital machine recordings, additionally the QT interval was measured manually with the help of caliper. ECGs were analyzed for any clinically significant ECG alteration. The concerned psychiatrist \&the patients were informed accordingly.

\section{Statistical analysis}

Statistical analysis was done by using Statistical software SPSS 17.0. Student's paired t-test was used to compare alterations in ECG parameters at the follow up visits if any, with that of the baseline ECG by individual drug under study. Also the differences in alterations in ECG parameters by individual drugs under study with respect to gender and different age groups were tested by comparing mean changes in ECG parameters from baseline in respective visits after drug treatment, with the help of $\mathrm{z}$ test and also for the differences in ECG alterations between two drug groups (escitalopram vs. sertraline). P-value of less than 0.05 was considered as statistically significant.

\section{RESULTS}

A total of 106 patients, those who were prescribed escitalopram and total of 103 patients those who were prescribed sertraline, were registered for the study. Out of which 12 patients from escitalopram group and 10 patients from sertraline were lost to follow-up. Hence the remaining 94 patients under escitalopram treatment, 93 patients under treatment of sertraline, attended all the scheduled follow up visits regularly and their ECG monitoring data is used for study analysis. Sociodemographic variables included in this study were sex and age of the patients receiving treatment with either escitalopram or sertraline. Patients were categorized into two age groups viz. 18-35 years and 36-50 years.

During visit II, 2 weeks after initiation of escitalopram we observed comparative increase in PR interval and $\mathrm{RR}$ interval when compared with respective baseline values, while rest all ECG parameters were comparatively decreased. But the overall difference was statistically nonsignificant (Table 1).

Table 1: Comparison between the values of different ECG parameters at the follow up visits and their respective values at baseline, in patients receiving treatment of escitalopram $(n=94)$.

\begin{tabular}{|lllll|l|}
\hline ECG parameter & Base-line :Visit I & Visit II 2 wks & p-value II / I & Visit III6 wks & p-value III / I \\
\hline HR (bpm) & $77.72 \pm 6.04$ & $77.27 \pm 6.13$ & $0.62 \mathrm{NS}$ & $78 \pm 6.24$ & $0.74 \mathrm{NS}$ \\
\hline PR (ms) & $156.31 \pm 14.63$ & $157.48 \pm 13.23$ & $0.57 \mathrm{NS}$ & $154.48 \pm 15.64$ & $0.40 \mathrm{NS}$, \\
\hline QRS (ms) & $85.42 \pm 10.18$ & $82.95 \pm 10.06$ & $0.09 \mathrm{NS}$ & $84.59 \pm 10.39$ & $0.55 \mathrm{NS}$ \\
\hline QT (ms) & $363 \pm 19.30$ & $358.23 \pm 18.70$ & $0.10 \mathrm{NS}$ & $361.36 \pm 18.90$ & $0.57 \mathrm{NS}$ \\
\hline RR (ms) & $777.19 \pm 60.67$ & $781.97 \pm 62.22$ & $0.59 \mathrm{NS}$ & $774.76 \pm 62.22$ & $0.77 \mathrm{NS}$ \\
\hline QTc (ms) & $409.12 \pm 22$ & $404.45 \pm 24.55$ & $0.09 \mathrm{NS}$ & $407.79 \pm 21.43$ & $0.74 \mathrm{NS}$ \\
\hline QTd (ms) & $24.28 \pm 10.03$ & $23.91 \pm 8.85$ & $0.80 \mathrm{NS}$ & $24.70 \pm 9.25$ & $0.76 \mathrm{NS}$ \\
\hline
\end{tabular}

During visit III, 6 weeks after initiation of escitalopram treatment we observed comparative increase in heart rate and QTd when compared with respective baseline values, while rest all ECG parameters were comparatively decreased. But the overall difference was statistically nonsignificant (Table 1).

There were no statistically significant differences in ECG alterations between the patients of these two age groups, treated with escitalopram in visit II as well as in visit III (Table 2).

The difference between mean changes from the baseline, in ECG parameters of male patients and that of the female patients was found to be statistically non-significant in both the follow up visits, visit II and visit III (Table 3). 
Table 2 : Comparison of mean changes from the baseline values in different ECG parameters, of patients in age group of 18-35 years $(n=57)$ with that of the patients in age group 36-50 years $(n=37)$, at the follow up visits after the treatment with escitalopram.

\begin{tabular}{|c|c|c|c|c|c|c|}
\hline \multirow{3}{*}{$\begin{array}{l}\text { ECG } \\
\text { parameter }\end{array}$} & \multirow{2}{*}{\multicolumn{2}{|c|}{$\begin{array}{l}\text { Mean changes from the baseline } \\
\text { in visit II } \\
\text { Mean change } \pm \text { SD }\end{array}$}} & \multirow{3}{*}{ p-value } & \multirow{2}{*}{\multicolumn{2}{|c|}{$\begin{array}{l}\text { Mean changes from the baseline } \\
\text { at the visit III } \\
\text { Mean change } \pm \text { SD }\end{array}$}} & \multirow{3}{*}{ p-value } \\
\hline & & & & & & \\
\hline & $18-35$ years & 36-50 years & & 18-35 years & 36-50 years & \\
\hline HR (bpm) & $0.85 \pm 7.97$ & $-2.45 \pm 9.45$ & $0.37, \mathrm{NS}$ & $0.98 \pm 7.61$ & $-0.81 \pm 8.91$ & $0.30, \mathrm{NS}$ \\
\hline PR (ms) & $-1.47 \pm 20.56$ & $5.24 \pm 19.29$ & $0.11, \mathrm{NS}$ & $-3.64 \pm 22.60$ & $0.97 \pm 18.73$ & $0.30, \mathrm{NS}$ \\
\hline QRS (ms) & $-1.12 \pm 14.48$ & $-4.54 \pm 13.63$ & $0.25, \mathrm{NS}$ & $0.77 \pm 13.75$ & $-3.29 \pm 13.30$ & $0.15, \mathrm{NS}$ \\
\hline QT (ms) & $-4.03 \pm 27.41$ & $-5.89 \pm 30.13$ & $0.75, \mathrm{NS}$ & $-1.36 \pm 28$ & $-2.05 \pm 28.71$ & $0.90, \mathrm{NS}$ \\
\hline $\mathbf{R R}(\mathrm{ms})$ & $-7.50 \pm 80.54$ & $23.72 \pm 95.71$ & $0.09, \mathrm{NS}$ & $-9.61 \pm 76$ & $8.64 \pm 88.60$ & $0.28, \mathrm{NS}$ \\
\hline QTc (ms) & $-4.28 \pm 4.20$ & $-5.35 \pm 3.86$ & $0.20, \mathrm{NS}$ & $-1.75 \pm 3.06$ & $-0.48 \pm 3.27$ & $0.056, \mathrm{NS}$ \\
\hline QTd (ms) & $-0.10 \pm 15.08$ & $-0.78 \pm 13.21$ & $0.82, \mathrm{NS}$ & $-0.84 \pm 13.29$ & $2.35 \pm 13.78$ & $0.26, \mathrm{NS}$ \\
\hline
\end{tabular}

Table 3: Comparison of mean changes from the baseline values of different ECG parameters of male patients $(n=44)$, with that of the female patients $(n=50)$, at the follow up visits after the treatment with escitalopram.

\begin{tabular}{|c|c|c|c|c|c|c|}
\hline \multirow{3}{*}{$\begin{array}{l}\text { ECG } \\
\text { parameters }\end{array}$} & \multirow{2}{*}{\multicolumn{2}{|c|}{$\begin{array}{l}\text { Mean changes from the baseline } \\
\text { at the visit II } \\
\text { Mean change } \pm \text { SD }\end{array}$}} & \multirow{3}{*}{ p-value } & \multirow{2}{*}{\multicolumn{2}{|c|}{$\begin{array}{l}\text { Mean changes from the base line } \\
\text { at the visit III } \\
\text { Mean change } \pm \text { SD }\end{array}$}} & \multirow{3}{*}{ p-value } \\
\hline & & & & & & \\
\hline & \multicolumn{2}{|c|}{$\begin{array}{l}\text { Mean change } \pm \text { SD } \\
\text { Male } \quad \text { Female }\end{array}$} & & Male & Female & \\
\hline HR (bpm) & $0.27 \pm 8.61$ & $-1.08 \pm 8.80$ & $0.45, \mathrm{NS}$ & $0.29 \pm 8.65$ & $0.26 \pm 7.77$ & $0.98, \mathrm{NS}$ \\
\hline PR (ms) & $3.54 \pm 21.29$ & $-0.92 \pm 19.23$ & $0.28, \mathrm{NS}$ & $-1.22 \pm 19.03$ & $-2.36 \pm 23.08$ & $0.79, \mathrm{NS}$ \\
\hline QRS (ms) & $-4.86 \pm 13.02$ & $-0.36 \pm 14.93$ & $0.12, \mathrm{NS}$ & $-2.13 \pm 13.34$ & $0.32 \pm 13.95$ & $0.38, \mathrm{NS}$ \\
\hline QT (ms) & $-0.45 \pm 28.31$ & $-8.56 \pm 28.14$ & $0.16, \mathrm{NS}$ & $2.77 \pm 30.23$ & $-5.52 \pm 25.83$ & $0.15, \mathrm{NS}$ \\
\hline RR (ms) & $-3.50 \pm 86.37$ & $12.08 \pm 89.04$ & $0.39, \mathrm{NS}$ & $-3.27 \pm 86.71$ & $-1.68 \pm 76.96$ & $0.92, \mathrm{NS}$ \\
\hline QTc (ms) & $-4.27 \pm 4.39$ & $-5.08 \pm 3.80$ & $0.34, \mathrm{NS}$ & $-1.56 \pm 3.03$ & $-0.98 \pm 3.32$ & $0.37, \mathrm{NS}$ \\
\hline QTd (ms) & $-2.25 \pm 14.79$ & $1.28 \pm 13.80$ & $0.23, \mathrm{NS}$ & $2.27 \pm 13.30$ & $-1.22 \pm 13.61$ & $0.21, \mathrm{NS}$ \\
\hline
\end{tabular}

Table 4: Comparison between the values of ECG parameters at the follow up visits and their respective values at baseline, in patients receiving treatment of sertraline $(n=93)$.

\begin{tabular}{|llllll|}
\hline ECG & Mean \pm SD & & & & \\
parameter & Base-line: visit I & Visit II 2 weeks & p-value II / I & Visit III: 6 weeks & p-value III/I \\
\hline HR (bpm) & $74.70 \pm 7.52$ & $75.32 \pm 7.41$ & $0.95 \mathrm{NS}$ & $76.08 \pm 7.35$ & $0.12 \mathrm{NS}$ \\
\hline PR (ms) & $156.53 \pm 14.19$ & $157.39 \pm 14.34$ & $0.56 \mathrm{NS}$ & $155.39 \pm 13.96$ & $0.50 \mathrm{NS}$ \\
\hline QRS(ms) & $81.61 \pm 8.58$ & $81.33 \pm 8.30$ & $0.80 \mathrm{NS}$ & $83.59 \pm 7.41$ & $0.07 \mathrm{NS}$ \\
\hline QT (ms) & $368.79 \pm 20.12$ & $366.25 \pm 20.14$ & $0.38 \mathrm{NS}$ & $366.30 \pm 17.96$ & $0.37 \mathrm{NS}$ \\
\hline RR (ms) & $801.46 \pm 72.40$ & $802.67 \pm 76.17$ & $0.89 \mathrm{NS}$ & $796.96 \pm 79.79$ & $0.66 \mathrm{NS}$ \\
\hline QTc(ms) & $406.32 \pm 21.99$ & $407.72 \pm 23.82$ & $0.42 \mathrm{NS}$ & $408.17 \pm 21.44$ & $0.79 \mathrm{NS}$ \\
\hline QTd (ms) & $29.55 \pm 11.26$ & $31.18 \pm 10.84$ & $0.30 \mathrm{NS}$ & $30.04 \pm 10.92$ & $0.77 \mathrm{NS}$ \\
\hline
\end{tabular}

During visit II, 2 weeks after initiation of sertraline treatment, we observed comparative decrease in QRS duration and QT interval when compared with respective baseline values while rest all ECG parameters were comparatively increased. But the overall difference was statistically nonsignificant (Table 4).

During visit III, 6 weeks after initiation of sertraline treatment we observed comparative decrease in PR and QT interval when compared to respective baseline values, while values of rest all ECG parameters were comparatively increased. But the overall difference was statistically nonsignificant (Table 4).
The differences between mean changes in ECG parameters from the baseline, in patients of age group 1835 years and that of the patients in age group 36-50 years were found to be statistically non-significant in visit II as well as in visit III, after treatment with sertraline (Table 5).

During visit II, 2 weeks after initiation of sertraline treatment, the differences between mean changes in ECG parameters from the baseline, of male patients and that of the female patients were statistically non-significant (Table 6). 
Table 5: Comparison of mean changes from the baseline, in ECG parameters of patients in age group of 18-35 years $(n=46)$, with that of the patients in age group 36-50 years $(n=47)$, at the follow up visits after the treatment with sertraline.

\begin{tabular}{|c|c|c|c|c|c|c|}
\hline \multirow{3}{*}{$\begin{array}{l}\text { ECG } \\
\text { parameter }\end{array}$} & \multirow{2}{*}{\multicolumn{2}{|c|}{$\begin{array}{l}\text { Mean changes from the baseline } \\
\text { in visit II } \\
\text { Mean change } \pm \text { SD }\end{array}$}} & \multirow{3}{*}{ p-value } & \multirow{2}{*}{\multicolumn{2}{|c|}{$\begin{array}{l}\text { Mean changes from the baseline in } \\
\text { visit II } \\
\text { Mean change } \pm \text { SD }\end{array}$}} & \multirow{3}{*}{ p-value } \\
\hline & & & & & & \\
\hline & 18-35 yrs & $36-50$ yrs & & 18-35 yrs & $36-50$ yrs & \\
\hline HR (bpm) & $0.67 \pm 8.54$ & $-0.78 \pm 12.21$ & $0.50, \mathrm{NS}$ & $0.56 \pm 8.32$ & $2.17 \pm 8.89$ & $0.37, \mathrm{NS}$ \\
\hline PR (ms) & $3.65 \pm 11.74$ & $-1.87 \pm 16.22$ & $0.06, \mathrm{NS}$ & $1.34 \pm 15.64$ & $-3.57 \pm 16.68$ & $0.14, \mathrm{NS}$ \\
\hline QRS (ms) & $0.17 \pm 10.52$ & $-0.72 \pm 11.30$ & $0.69, \mathrm{NS}$ & $3.17 \pm 10.58$ & $0.80 \pm 10.58$ & $0.28, \mathrm{NS}$ \\
\hline QT (ms) & $-1.86 \pm 23.53$ & $-3.19 \pm 32.38$ & $0.82, \mathrm{NS}$ & $-1.43 \pm 22.84$ & $-3.53 \pm 30.48$ & $0.70, \mathrm{NS}$ \\
\hline RR (ms) & $2.82 \pm 90.74$ & $-0.36 \pm 86.38$ & $0.86, \mathrm{NS}$ & $3.60 \pm 96.87$ & $-12.42 \pm 101.49$ & $0.43, \mathrm{NS}$ \\
\hline QTc (ms) & $0.86 \pm 3.24$ & $2.02 \pm 5.21$ & $0.20, \mathrm{NS}$ & $2.67 \pm 3.11$ & $1 \pm 2.15$ & $0.79, \mathrm{NS}$ \\
\hline QTd (ms) & $0.32 \pm 16.42$ & $2.89 \pm 14.16$ & $0.42, \mathrm{NS}$ & $0.86 \pm 16.98$ & $0.10 \pm 15.89$ & $0.82, \mathrm{NS}$ \\
\hline
\end{tabular}

Table 6: The comparison of mean changes from the baseline in ECG parameters of male patients $(n=42)$, with that of the female patients $(n=51)$, at the follow up visits after the treatment with sertraline.

\begin{tabular}{|c|c|c|c|c|c|c|}
\hline \multirow{3}{*}{$\begin{array}{l}\text { ECG } \\
\text { parameters }\end{array}$} & \multirow{2}{*}{\multicolumn{2}{|c|}{$\begin{array}{l}\text { Mean changes from the baseline in } \\
\text { Visit II } \\
\text { Mean change } \pm \text { SD }\end{array}$}} & \multirow{3}{*}{ p-value } & \multirow{2}{*}{\multicolumn{2}{|c|}{$\begin{array}{l}\text { Mean changes from the baseline } \\
\text { in Visit III } \\
\text { Mean change } \pm \text { SD }\end{array}$}} & \multirow{3}{*}{ p-value } \\
\hline & & & & & & \\
\hline & Male & Female & & Male & Female & \\
\hline HR (bpm) & $-0.38 \pm 8.45$ & $0.19 \pm 12.04$ & $0.79, \mathrm{NS}$ & $0.57 \pm 9.42$ & $2.03 \pm 7.90$ & $0.41, \mathrm{NS}$ \\
\hline PR (ms) & $1.71 \pm 13.17$ & $0.15 \pm 15.39$ & $0.60, \mathrm{NS}$ & $-0.61 \pm 17.52$ & $-1.56 \pm 15.34$ & $0.78, \mathrm{NS}$ \\
\hline QRS (ms) & $1.23 \pm 10.65$ & $-1.52 \pm 10.99$ & $0.22, \mathrm{NS}$ & $0.52 \pm 10.93$ & $-0.11 \pm 9.92$ & $0.08, \mathrm{NS}$ \\
\hline QT (ms) & $-1.47 \pm 28.83$ & $-3.41 \pm 27.94$ & $0.74, \mathrm{NS}$ & $-1.09 \pm 27.19$ & $-3.64 \pm 26.78$ & $0.65, \mathrm{NS}$ \\
\hline RR (ms) & $12.57 \pm 90.09$ & $-8.13 \pm 86.18$ & $0.26, \mathrm{NS}$ & $4.42 \pm 107.20$ & $-11.84 \pm 92.17$ & $0.43, \mathrm{NS}$ \\
\hline QTc (ms) & $4.47 \pm 3.43$ & $-1.03 \pm 3.38$ & $0.08, \mathrm{NS}$ & $2.11 \pm 1.59$ & $1.58 \pm 3.47$ & $0.36, \mathrm{NS}$ \\
\hline QTd (ms) & $3.83 \pm 15.03$ & $-0.19 \pm 15.41$ & $0.20, \mathrm{NS}$ & $-0.69 \pm 15.05$ & $1.45 \pm 17.44$ & $0.53, \mathrm{NS}$ \\
\hline
\end{tabular}

Table 7 : Comparison of mean changes from the baseline values of different ECG parameters, during follow up visits, in patients after treatment with escitalopram $(n=94)$ with that of the patients under treatment of sertraline $(\mathbf{n}=93)$.

\begin{tabular}{|c|c|c|c|c|c|c|}
\hline \multirow{3}{*}{$\begin{array}{l}\text { ECG } \\
\text { parameters }\end{array}$} & \multirow{2}{*}{\multicolumn{2}{|c|}{$\begin{array}{l}\text { Mean change from the baseline } \\
\text { at the visit II } \\
\text { Mean change } \pm \text { SD }\end{array}$}} & \multirow{3}{*}{ p-value } & \multirow{2}{*}{\multicolumn{2}{|c|}{$\begin{array}{l}\text { Mean change from the baseline at } \\
\text { the visit III } \\
\text { Mean change } \pm \text { SD }\end{array}$}} & \multirow{3}{*}{ p-value } \\
\hline & & & & & & \\
\hline & Escitalopram & Sertraline & & Escitalopram & Sertraline & \\
\hline HR (bpm1) & $-0.44 \pm 8.69$ & $-0.06 \pm 10.52$ & $0.78, \mathrm{NS}$ & $0.27 \pm 8.15$ & $1.37 \pm 8.60$ & $0.37, \mathrm{NS}$ \\
\hline PR (ms) & $1.17 \pm 20.23$ & $0.86 \pm 14.37$ & $0.90, \mathrm{NS}$ & $-1.82 \pm 21.18$ & $-1.13 \pm 16.28$ & $0.80, \mathrm{NS}$ \\
\hline QRS(ms) & $-2.46 \pm 14.18$ & $-0.27 \pm 10.87$ & $0.23, \mathrm{NS}$ & $-0.82 \pm 13.65$ & $1.97 \pm 10.59$ & $0.11, \mathrm{NS}$ \\
\hline QT (ms) & $-4.76 \pm 28.36$ & $-2.53 \pm 28.21$ & $0.59, \mathrm{NS}$ & $-1.63 \pm 28.13$ & $-2.49 \pm 26.85$ & $0.83, \mathrm{NS}$ \\
\hline $\mathbf{R R}(\mathbf{m s})$ & $4.78 \pm 87.68$ & $1.21 \pm 88.10$ & $0.78, \mathrm{NS}$ & $-2.42 \pm 81.22$ & $-4.49 \pm 99.02$ & $0.87, \mathrm{NS}$ \\
\hline QTc(ms) & $-4.70 \pm 4.08$ & $-4.65 \pm 4.08$ & $0.93, \mathrm{NS}$ & $-1.25 \pm 3.18$ & $-1.25 \pm 3.20$ & $0.99, \mathrm{NS}$ \\
\hline QTd (ms) & $-0.37 \pm 14.30$ & $1.62 \pm 15.29$ & $0.35, \mathrm{NS}$ & $0.41 \pm 13.50$ & $0.48 \pm 16.35$ & $0.97, \mathrm{NS}$ \\
\hline
\end{tabular}

During visit III, 6 weeks after initiation of sertraline treatment, the differences between mean changes in ECG parameters from the baseline, of male patients and that of the female patients were statistically non-significant (Table 6). None of the patients under treatment of either of the drugs under study showed prolongation of QTc more than $450 \mathrm{~ms}$.
When QTc values from follow up ECG recordings were compared with that of the baseline, the extremes of changes in QTc were seen $-4.4 \mathrm{~ms}$ to $+3 \mathrm{~ms}$ in escitalopram group and $-2 \mathrm{~ms}$ to $+6 \mathrm{~ms}$ in sertraline group (Table 8). 
Table 8: Maximum change in QTc interval after treatment with individual drug.

\begin{tabular}{|c|c|c|}
\hline \multicolumn{3}{|c|}{$\begin{array}{l}\text { Maximum change in QTc interval after treatment } \\
\text { with }\end{array}$} \\
\hline & Escitalopram & Sertraline \\
\hline QTc prolongation & $+3 \mathrm{~ms}$ & $+6 \mathrm{~ms}$ \\
\hline QTc shortening & $-4.4 \mathrm{~ms}$ & $-2 \mathrm{~ms}$ \\
\hline
\end{tabular}

\section{DISCUSSION}

\section{Escitalopram therapy and ECG changes:}

The values of ECG parameters after escitalopram treatment were altered as compared to their respective baseline values, but the alterations in the values of all the ECG parameters during all the visits were statistically not significant (Table 1).

The heart rate after treatment with escitalopram remained in the range of 77 to $78 \mathrm{bpm}$ in both the follow up visits. The change in heart rate was statistically non-significant.

This finding is in contrast with the reports of Thase et al showing statistically significant $2 \mathrm{bpm}$ decrease in heart rate with escitalopram compared with placebo. ${ }^{9}$

Although the maximum change in QTc after treatment with escitalopram in our study results was shortening of QTc with $4.4 \mathrm{~ms}$, it was statistically non-significant \&clinically non-significant as well (Table 8). This finding is in line with findings of Thase et al, who reported that the differences in mean changes in ECG values were not clinically meaningful. ${ }^{9}$

However our findings in respect to non-significant QTc alterations after escitalopram therapy were in contrast with the findings of Castro et al. They reported statistically significant $(\mathrm{p}<0.001)$ QTc prolongation associated with increasing dose of escitalopram. ${ }^{17}$ (10.7 $\mathrm{ms}$ with $30 \mathrm{mg} / \mathrm{dy}$ as compared to $4.5 \mathrm{~ms}$ with $10 \mathrm{mg} /$ day).

Tseng et al reported QTc prolongation in middle aged female at the dose of $5 \mathrm{mg}$ /day which was returned to normal after discontinuation of escitalopram. ${ }^{6}$

Furthermore we also compared the differences in ECG alterations from the baseline after escitalopram treatment between the patients of different age groups viz. 18-35 years and 36-50 years (Table 2) as well as between the male and female patients (Table 3) which were found to be statistically non-significant. This implies that there are no risk differences among different age groups as well as either gender of patients for ECG alteration after treatment with escitalopram.

Since none of the patients in our study had a QTc interval more than $500 \mathrm{~ms}$ or an isolated prolongation $>60 \mathrm{~ms}$ from baseline (Table 8). This finding is in line with the Stoppler et al. ${ }^{11}$

\section{Sertraline therapy and ECG changes}

After sertraline treatment the heart rate was increased from baseline value of $74.7 \mathrm{bpm}$ to $76.1 \mathrm{bpm}$ in visit III (Table 4) but the change was statistically non-significant. The alterations in values of rest all ECG parameters after treatment with Sertraline were found to be statistically non-significant.

This finding is in line with the report of Fisch et al, Wilens et al. ${ }^{18,11}$ Although the maximum change in QTc after treatment with sertraline in the study results was prolongation of QTc by $6 \mathrm{~ms}$, (Table 8) it was statistically non-significant and clinically non-significant as well.

However this was in contrast with the findings of Castro et al, furthermore we also compared the differences in ECG alterations from the baseline after sertraline treatment between the patients of different age groups viz. 18-35 years and that $36-50$ years (Table 5) as well as between male and female (Table 6) patients which were found to be statistically nonsignificant. ${ }^{17}$ This implies that that there is no risk differences among different age groups as well as either gender of patients for ECG alteration after treatment with sertraline, in our study.

Although Sertraline appeared to have no cardiac adverse effects throughout the study, but there are certain reports in contrast to this.

- Case report of sudden death of a 26-year-old white man under treatment of Sertraline and clozapine, since his treatment regimen included multiple drugs like clozapine (100 $\mathrm{mg}$ bid), risperidone ( $3 \mathrm{mg}$ bid), sertraline (200 mg o.d.), atenolol (50 mg bid) and lorazepam $(0.5 \mathrm{mg}$ qid $)$, hence postulating the sertraline as a cause for his death cannot be justified. ${ }^{19}$

- Case report of a 50-year-old male patient, whose treatment switched from citalopram $(10 \mathrm{mg} /$ day $)$ to $50 \mathrm{mg} /$ day of sertraline, developed sinus arrest. Although the fact was that his treatment was switched from citalopram to sertraline without any washout period, hence serotonin syndrome could be the reason behind this arrest. ${ }^{20}$

- Most of the study reports mention sertraline as free from any significant cardiovascular adverse effects. Which made researcher to test its cardiac safety in patients of post myocardial infarction and coronary syndromes, for example Glassman et al proved cardiac safety of sertraline in those patients with recent MI or unstable angina. ${ }^{10}$ Most importantly if clinicians tended to prescribe sertraline to patients who had experienced myocardial infarction on the basis of the Sadhart or Sadhart-CHF trials, a 
spurious association between sertraline and ECG changes like QT prolongation might be observed. ${ }^{10,21}$

\section{Comparison between escitalopram and sertraline}

The ECG alterations caused by the escitalopram were compared with that caused by sertraline (Table 7).

It was observed that the differences between the ECG alterations caused by either of escitalopram or sertraline are statistically nonsignificant.

\section{Pro-arrhythmic potential of drugs under study}

The pro-arrhythmic potential of drugs under study was assessed by comparing the values of QTc interval observed during study with that of the various guidelines given for QTc as follows:

- By the definition given by Moss et al, none of the patients under treatment of drugs under study showed prolongation of QTc more than $450 \mathrm{~ms}^{22}$

- According to Stollberger et al and Harrigan et al criteria, none of the patients in our study have a QTc interval more than $500 \mathrm{~ms}$, (Table 8) hence none of the drugs under study has potential risk of torsades de pointes $(\mathrm{TdP}){ }^{23,24}$

- There are various suggestions regarding extent of QTc prolongation by the drug and risk of drug induced arrhythmias, like

1. Committee for proprietary medicinal products (CPMP) suggested that individual changes of QTc length of between 30 and $60 \mathrm{~ms}$ from baseline raises concern for the potential risk of drug induced arrhythmias. ${ }^{25}$

2. Guidance for industry: E14 saying that the drugs that prolong the mean QT/QTc interval by $>20$ $\mathrm{ms}$ have a substantially increased likelihood of being pro-arrhythmic. ${ }^{26}$

3. Shockley's drug interactions quoted that change in baseline QTc of $>20 \mathrm{~ms}$ should raise concern and a change of $>60 \mathrm{~ms}$ should raise greater concern regarding the potential for arrhythmias. ${ }^{27}$

4. Since none of the patients in our study showed QTc prolongation in any of range mentioned above (Table 8) hence we conclude that, at therapeutic doses of neither of the drugs under study, have the potential risk of drug induced arrhythmias, throughout the study. ${ }^{1,2,3}$

The study has some limitations, most of them related to the naturalistic setting of this study:

- Short duration of study, lack of placebo arm \&lack of random assignment of treatment would have affected results of study up to some extent.
- Furthermore, the doses of the drugs administered throughout the study can be considered as low but as these doses are clinically determined by psychiatrist depending upon patients' initial symptoms \&improvement of symptoms during follow up visits. Also the doses varied within \&between different drug groups because of individualised drug dosing by the psychiatrist.

- We didn't measure serum levels of drugs under study.

- Since the values most of the ECG parameters were automatically calculated by the ECG machine, the instrumental error cannot be ignored.

- $\quad$ Patients included in study were in the age group 1850 years and were strictly on monotherapy for very short duration. Hence with long term use of these drugs and further advancing age might show more significant changes in ECG parameters.

\section{Imapct of the study}

It was evident in our study that the patients and their parents coming for subsequent follow ups, they were more concerned regarding their cardiovascular wellbeing. The psychiatrist became more vigilant regarding the cardiovascular safety of patient and started inquiring $\&$ taking all the related history before prescribing the individual drug to patient. The department of psychiatry also decided to do the ECG monitoring accordingly for individual drugs in patients considered to be at high risk. This attitude of psychiatrist was continued even after the completion of our study.

\section{CONCLUSION}

This imparting of knowledge can definitely help in curbing cost of treatment, better clinical outcome and compliance of the patients.

Further observational multicentre studies on larger samples of patients, correlating long term use related cardiovascular adverse effects, plasmatic levels \&daily doses of these drugs in children, pregnant females, subjects with co morbid cardiovascular and other systemic illnesses and substance abuse patients are necessary. So that the statistical comparisons between these drugs as well as their combinations with other psychotropic drugs can be explored.

\section{Funding: No funding sources \\ Conflict of interest: None declared}

Ethical approval: The study was approved by the Institutional Ethics Committee 


\section{REFERENCES}

1. Grover S, Kumar V, Avasthi A, Kulhara P. An audit of first prescription of new patients attending a psychiatry walk-in-clinic in north India. Indian $\mathrm{J}$ Pharmacol. 2012;44(3):319-25.

2. Taylor D. Antidepressant drugs and cardiovascular pathology: a clinical overview of effectiveness and safety. Acta Psychiatr Scand. 2008;118:434-42.

3. Witchel HJ, Hancox JC, Nutt DJ, Witchel HJ, Hancox JCND. Psychotropic drugs, cardiac arrhythmia, and sudden death. J Clin Psychopharmacol. 2003;23(1):58-77.

4. Pacher P, Kecskemeti V, Pal PVK. Cardiovascular side effects of new antidepressants and antipsychotics: new drugs, old concerns? Curr Pharm Des. 2004;10(20):2463-75.

5. Castro VM, Clements CC, Murphy SN. QT interval and antidepressant use : a cross sectional. 2013;288:1-11.

6. Tseng PT, Lee Y, Lin YE, Lin PY. Low-dose escitalopram for 2 days associated with corrected QT interval prolongation in a middle-aged woman: a case report and literature review. Gen Hosp Psychiatry. 2012;34(2):210-3.

7. Kocabay G, Yildiz M, Eksi Duran N, Ozkan M, Duran NE. Sinus arrest due to sertraline. Clin Cardiol. 2010;33(6):114-5.

8. Hanash JA, Hansen BH, Hansen JF, Nielsen OW, Rasmussen A, Birket SM. Cardiovascular safety of one-year escitalopram therapy in clinically nondepressed patients with acute coronary syndrome: results from the depression in patients with coronary artery disease (DECARD) trial. J Cardiovasc Pharmacol. 2012;60(4):397-405.

9. Thase ME, Larsen KG, Reines E, Kennedy SH. The cardiovascular safety profile of escitalopram. Eur Neuropsychopharmacol. 2013;23(11):1391-400.

10. Glassman AH, Oconnor CM, Califf RM, Swedberg K, Schwartz P, Bigger Jr JT, et al. Sertraline treatment of major depression in patients with acute MI or unstable angina. J Am Asso. 2002;288(6):7019 .

11. Wilens TE, Biederman J, March JS, Wolkow R, Fine CS, Millstein RB, et al. Absence of cardiovascular adverse effects of sertraline in children and adolescents. J Am Acad Child Adolesc Psychiatry. 1999;38(5):573-7.

12. Okin PM, Devereux RB, Howard BV. Assessment of QT interval and QT dispersion for prediction of all-cause and cardiovascular mortality in American Indians: Strong Hear Study Circ. 2000;101:61-6.

13. Rabkin SW. Electrocardiographic abnormalities in apparently healthy men and the risk of sudden death. Drugs. 1984;28:28-45.

14. Lingeswaran A, Harshashetty, Kigshuklohan, Amitparamel SG. A letter to the editor. Ind J Ppharmacol. 2010;42.
15. Littmann L, Monroe MH. Brugada-type electrocardiographic pattern induced by cocaine. Mayo Clic Proc. 2000;75:845-9.

16. Daga B, Minano A, Puerta I, Pelegrin J, Rodrigo G. Electrocardiographic findings typical of brugada syndrome unmasked by cocaine consumption. Rev Esp Cardiol. 2005;58:1355-7.

17. Castro VM, Clements CC, Murphy SN, Gainer VS, Fava M, Weilburg JSB, et al. QT interval and antidepressant use: a cross sectional study of electronic health records. British Med J. 2013;346:288.

18. Fisch C, Knoebel SB. Electrocardiographic findings in sertraline depression trials. Drug Investig. 1992;4(4):305-12.

19. Hoehns JD, Fouts MM, Kelly MW, Tu KB. Sudden cardiac death with clozapine and sertraline combination. Ann Pharmacother. 2001;35(7):862-6.

20. Kocabay G, Yildiz M, Eksi DN, Ozkan M. Sinus arrest due to sertraline. Clin Cardiol. 2010;33(6):114-5.

21. Jiang W, Oconnor C, Silva SG, Kuchibhatla M, Cuffe MS, Callwood DD, et al. Safety and efficacy of sertraline for depression in patients with $\mathrm{CHF}$ (SADHART-CHF): a randomized, double-blind, placebo-controlled trial of sertraline for major depression with congestive heart failure. Am Heart J. 2008;156(3):437-44.

22. Moss AJ. Measurement of the QT interval and the risk associated with QTc interval prolongation: a review. Am J Cardiol. 1993;72:23-5.

23. Stollberger C, Huber JO, Stollberger C, Huber JO, Finsterer J. Antipsychotic drugs and QT prolongation. Int Clin Psychopharmacol. 2005;20(5):243-51.

24. Harrigan EP, Miceli JJ, Anziano R, Watsky E, Reeves KR, Cutler NR et al. A randomized evaluation of the effects of six antipsychotic agents on QTc, in the absence and presence of metabolic inhibition. J Clin Psychopharmacol. 004;24:62-9.

25. Committee for proprietary medicinal products (CPMP). points to consider: the assessment of the potential for QT interval prolongation by noncardiovascular medicinal products. Eur. Agency Eval Med Prod. 1997;Available from: http://www.fda.gov/ohrms/dockets/ac/03/briefing/pu bs/cpmp.pdf. Accessed on 12 February 2016.

26. Administration USF and D. Guidance for industry: E14 clinical evaluation of QT/QTc interval prolongation and proarrhythmic potential for nonantiarrhythmic drugs. Food Drug Adm. 2005

27. Stockley's drug interactions. Available at www.medicinescomplete.com. Accessed on 12 February 2016.

Cite this article as: Choure BK, Raparti GT, Ramanand JB, Tapase JB, Patil PT, Puram NN, et al. Comparison of cardiovascular safety of escitalopram and sertraline based on electrocardiographic alterations: a pharmacovigilance study. Int J Basic Clin Pharmacol 2016;5:1193-1200. 